\title{
Elastohydrodynamic Lubrication Analysis on the Performance of Artificial Hip Joint for Sitting ("Iftirasy") Movement in Muslim Prayer (Salat) Activity
}

\author{
Jamari $^{1}$ Mohammad Tauviqirrahman ${ }^{1, *}$ Havilla Rizieq Husein ${ }^{1}$ Muchammad $^{1}$
}

\author{
${ }^{1}$ Department of Mechanical Engineering, Diponegoro University, 50275, Indonesia
}

*Corresponding author. Email: mtauviq99@lecturer.undip.ac.id

\begin{abstract}
The patients of artificial hip joint are recommended to limit the extreme movements that could cause damage of the device, such as salat movement. As many studies performed the simulation by neglecting the presence of synovial fluid, in this study, we examined the performance of artificial hip joint under the elastohydrodynamic lubrication model which close to realistic conditions. This research aimed to investigated the effect of the existence of the lubricant in the artificial hip joint on the lubrication performance including the structure analysis during sitting ("Iftirasy") salat movement to accommodate the major religious practice of Muslim community. Fluid-Structure Interaction (FSI) method employed to solve the elastohydrodynamic lubrication in the artificial hip joint during sitting (right and left leg) positions. The results show that in order to obtain a more accurate result, the lubricant of the synovial fluid should be considered and modeled. Additionally, the existence of the lubricant is proven to prevent solid contact as well as impingement between the component. The opposing trend result of the lubrication performance analysis between right and left leg on sitting between two prostration movement require further investigations.
\end{abstract}

Keywords: Artificial Hip Joint, Synovial Fluid, Elastohydrodynamic Lubrication, Computational Fluid Dynamic (CFD), fluid-Structure Interaction (FSI), Muslim Prayer (Salat).

\section{INTRODUCTION}

Nowadays, many factors lead to various disorders of the hip joint, in severe cases, pain and several diseases may occur at the joints of pelvis bone which could result from having difficulty moving the legs to even barely able to walk. Partial or permanent damage of the hip joint due to aging, infection, or an accident often requiring replacement with an artificial hip joint. To prevent the shortcoming, the patients are recommended to limit the movements. Potential activity such as squatting, running, and Muslim prayer (salat) for instance, may trigger the dislocation and impingement of the artificial hip joint. In order to reduce the possible experience, few researchers in the Engineering Design and Tribology Laboratory of Diponegoro University were managed to develop the bipolar type of the artificial hip joint to be used to bear the Muslim prayer (salat) loading for the Muslim inherent in Indonesia.
In general, some developed model among the authors that able to analyze the tribological performance of artificial hip joint and result an interesting finding have been found in literature review. Research conducted in [1] has evaluated the limitations of artificial hip joint under several Muslim prayer (salat) movement with an aim on the reactions force received by the acetabular liner and femoral head. Meanwhile, Dhaneswara et al. [2] has simulated the effect of the clearance existence to examine the wear and impingement with identical model and loading conditions from previous studies. Recently, in [3] observed the static analysis under walking and salat movements of the reactions force that occurred. A more detailed analysis performed by Eko et al. [4], they compared the performance for two types of activities: Western style and Japanese style, resulting the occurred collision between components only found in Western style.

The mentioned studies above, however, are only focus on the structural analysis of solid domain (dry 
contact) which neglecting any lubrication fluid in the gap between acetabular liner and femoral ball. Whereas in reality, the synovial fluid that act as lubricant occurs naturally in the body, notably, have a significant effect in the performance of the artificial hip joint [5-9]. In short, the dry contact analysis becomes less relevant and can lead to inaccurate withdrawal conclusions of the research. Hence, based on the previous studies, the main purpose of this study is to analyze the influence of the presence of synovial fluid on lubrication characteristics such as hydrodynamic pressure, von Mises stress, and deformation of artificial hip joint. The performance of artificial hip joint during sitting ("Iftirasy") Muslim prayer (Salat) movement are the particular interest of this study. The two-way Fluid-Structure Interaction (FSI) analysis method is employed to examine the characteristic and to accommodate more realistic result.

\section{METHOD}

The model was solved by two-way fluid-structure interaction (FSI) techniques, a numerically coupled simulations of computational fluid dynamic (CFD) package and structural analysis (FEM) in ANSYS Workbench software. Elastohydrodynamic analysis allow changes in the lubrication film thickness, initially, the fluid flow was performed first, and then the result was imported as an input load to the structural analysis, thus, it will affect the result of the fluid pressure. Finally, deformation occurs as the solid response, and this cycle is repeated simultaneously until both solution convergences.

\subsection{Geometry Model of Artificial Hip Joint}

In the present study, the artificial hip joint consists of a rotating femoral head in lubricated acetabular cup. Figure 1 shows the components schematic of the model.

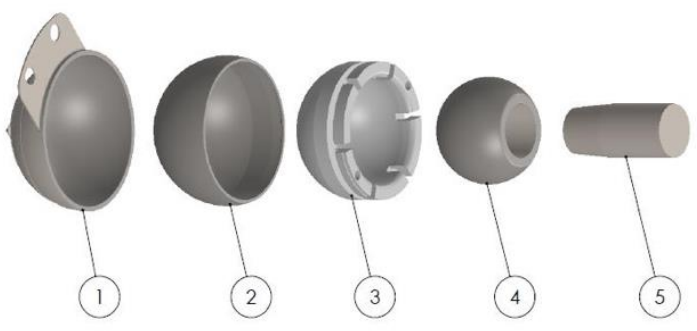

Figure 1 Artificial hip joint components (Note: 1. Acetabular Cup; 2. Outer Liner; 3. Inner Liner; 4. Femoral Head; 5. Stem).

The angle positions are obtained by rotating the position the femoral head which measured based on the anatomical position (standing position) of the artificial hip joint. Thus, for the sitting movement, the angle positions of the model are shown in Table 1. Figure 2 show artificial hip joint model on sitting ("Iftirasy") movement.

Table 1. Angle positions of sitting between two prostrations.

\begin{tabular}{|c|c|c|c|}
\hline \multirow{2}{*}{ Position } & \multicolumn{3}{|c|}{ Angle Positions $\left({ }^{\circ}\right)$} \\
\hline & Flexion $(\mathrm{X})$ & Abduction (Y) & Rotation $(\mathrm{Z})$ \\
\hline \multicolumn{4}{|c|}{ Sitting between two prostrations: } \\
\hline Right leg & 91.6 & 9.14 & 23 \\
\hline Left leg & 87.2 & -8.9 & 18 \\
\hline
\end{tabular}
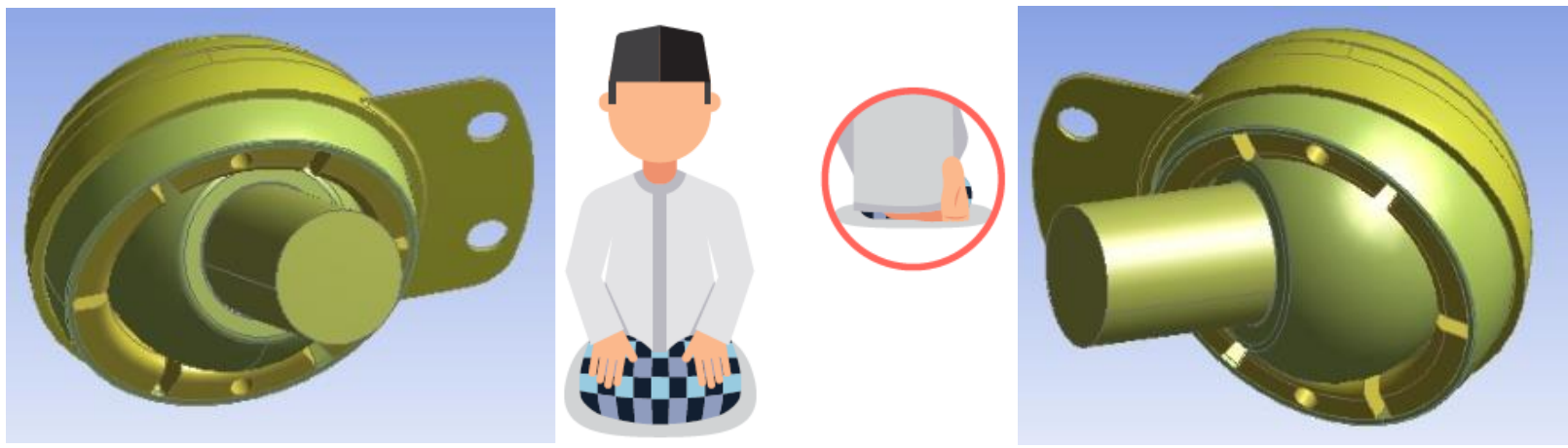

Figure 2 Artificial hip joint model on sitting ("Iftirasy") movement.

\subsection{Boundary Conditions}

The model is assumed having two no-slip surface boundary conditions. Figure 3 present the detail of boundary conditions used. The synovial fluid is modeled as non-Newtonian proposed by Cross. with the zero shear rate viscosity of $=40 \mathrm{~kg} / \mathrm{m}-\mathrm{s}$, power-law index of $\mathrm{n}=$ 0.27 , time constant of $=9.54 \mathrm{~s}$, density of $\rho=1010 \mathrm{~kg} / \mathrm{m}^{3}$. 


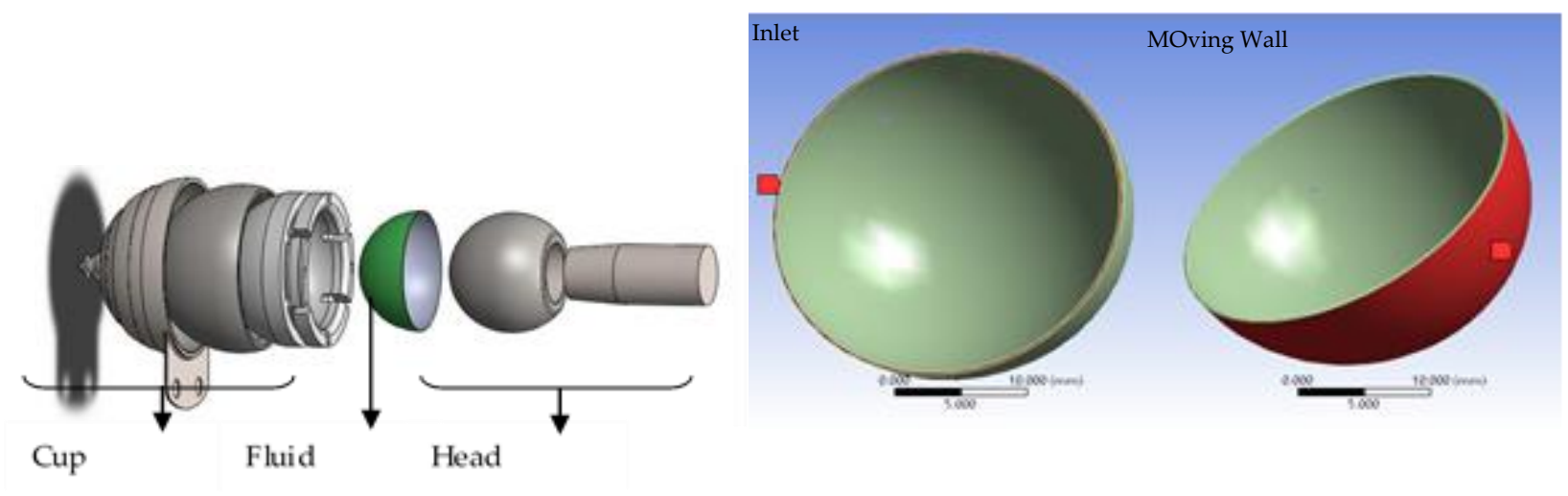

(a)

(b)

Figure 3 Boundary conditions of lubrication analysis: (a) Location of lubrication region in the artificial hip joint model; (b) Inlet, moving wall and stationary wall.

In the present study, the velocity input for the boundary condition on sitting right and left leg) positions are required to define the artificial hip joint movements at three directions. Table 2 shown Velocity vector component on sitting ("Iftirasy") (Right and left leg) position.

Table 2. Velocity vector component on sitting ("Iftirasy") (Right and left leg) position.

\begin{tabular}{lccc} 
& \multicolumn{3}{c}{ Velocity Component $(\mathrm{m} / \mathrm{s})$} \\
Pitting ("Iftirasy") & Flexion $(\mathrm{X})(\mathrm{m} / \mathrm{s})$ & Abduction $(\mathrm{Y})(\mathrm{m} / \mathrm{s})$ & Rotation $(\mathrm{Z})(\mathrm{m} / \mathrm{s})$ \\
Right leg & & & \\
Left leg & 0.011231 & 0.001121 & 0.002820 \\
\hline
\end{tabular}

The outer surface of acetabular cup set to fixed. The system coupling techniques requires contact definition of the area on the solid and fluid surface that has direct contact with synovial fluid as presented in Figure 3a. In this work, the model has been chosen and validated based on the independent mesh study.

\section{RESULT AND DISCUSSION}

\subsection{Lubrication Performance Synovial Fluid}

In this section the results are shown, the input parameter that represented in Table 1 and 2 with the twoway FSI method was numerically simulated. Figure 4 shows the contour of hydrodynamic pressure distribution generated by the synovial fluid for sitting between two prostrations (right leg and left leg) movement. The red contours are indicating the pressure difference relatively higher at particular area and vice versa, that is caused by the affected direction of the applied force during the movement. The result varies at right and left leg positions, the hydrodynamic pressure distribution plot of the right leg appeared to be in the positive region and the left leg fall below zero, as shown in Figure 5. From a physical point of view, at right leg position, this imply the synovial fluid model is able to bear the external loads of the movement. However, on sitting (left leg) position displayed the lubricant model is inadequate to withstand the loads as it shows the entire fluid pressure plot fall into the negative region. It is important to note that these two findings take place at the steady state with identical loading condition that represent one-instantaneousmovement, the maximum hydrodynamic pressure occurred at $115^{\circ}$ angle position on sitting (right leg) movement and at $60^{\circ}$ angle position for left leg with a reflective half sine-alike plot across $\mathrm{x}$-axis. Therefore, the lubrication performance for sitting movement is insufficient that require further study of load support investigation. 


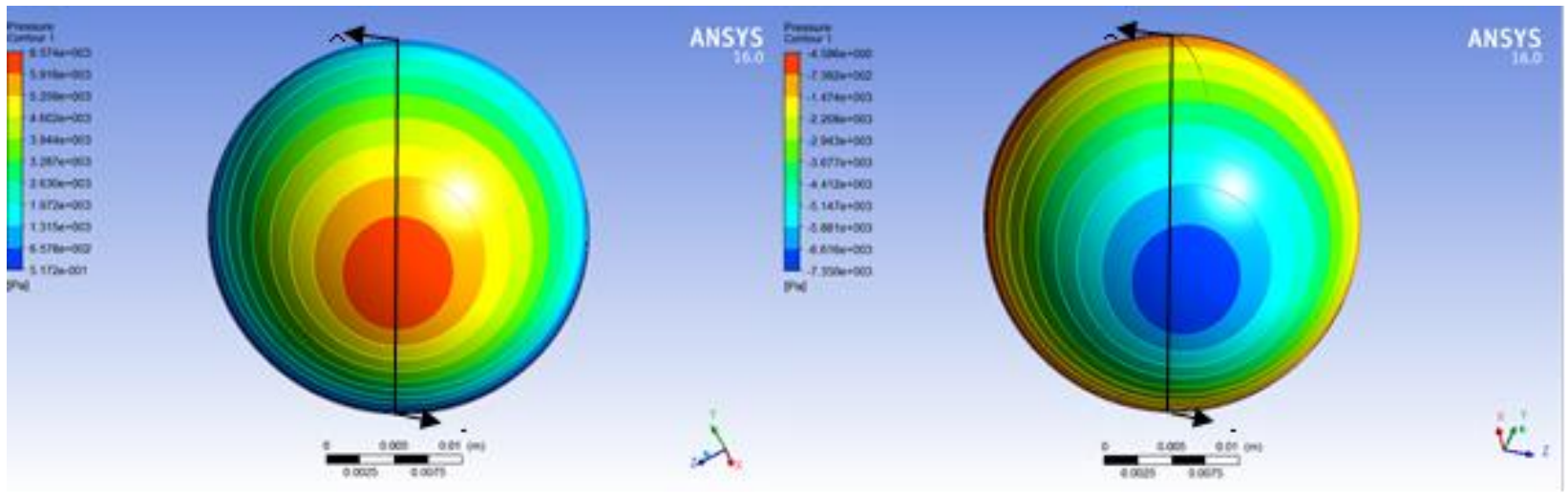

(a)

(b)

Figure 4 The hydrodynamic pressure distribution contour on siting between two prostrations movement: (a) right leg; (b) left leg.

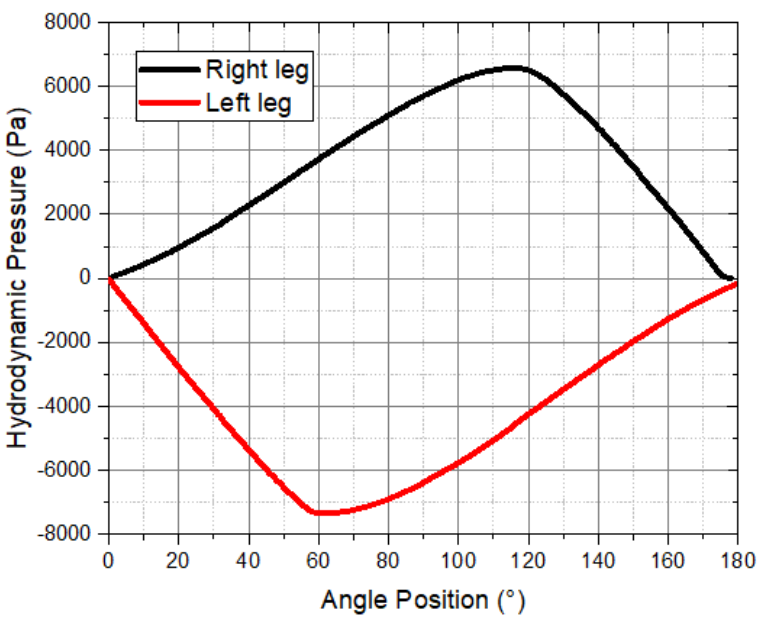

Figure 5 The hydrodynamic pressure plot on sitting (right and left leg) movement.

\subsection{Stress and Deformation of Solid Domain}

Based on the finite element analysis in solid domain as shown in Figure 6, 7 and Table 3. The von Mises stress contours as displayed in Figure 6 indicates the stress distribution represented by the contour color, the maximum stress under sitting ("Iftirasy") loading condition both occurred at the outer surface of outer liner component that marked by red color which is equal to 3.09 $\mathrm{MPa}$ on right leg and 4.61 MPa on left leg. Refers to the result of the dry contact analysis conducted by Gapa [3] compared with the present study, there is a significant difference of the von Mises stress result which up to $3768.53 \%$ on the right leg and $2726.92 \%$ on the left leg during sitting movement, as shown in Table 3 . This could be explained by the influence of synovial fluid as a lubricant that filled in the gap between acetabular liner and femoral head managed to significantly reduce the applied loads in artificial hip joint component. In short, the elastohydrodynamic lubrication model could remarkably anticipated the possibility of the collision between two solid components (impingement) and potentially reduce the friction of the solid domain.

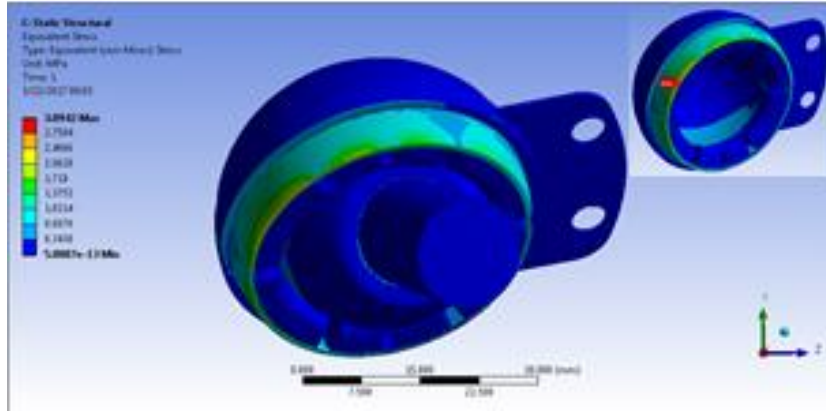

(a)

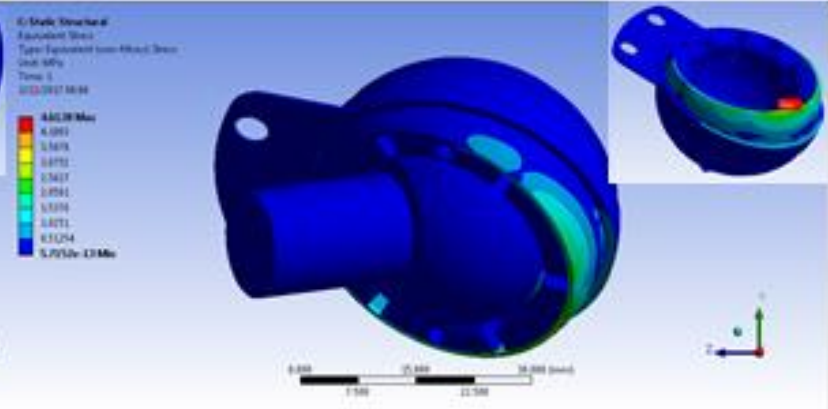

(b)

Figure 6 The von Mises stress contour on sitting movement: (a) Right leg; (b) Left leg. 
Table 3. Comparison of the dry contact and elastohydrodynamic model.

\begin{tabular}{lllc}
\multicolumn{1}{c}{ Position } & \multicolumn{2}{c}{$\begin{array}{c}\text { Maximum Stress (MPa) } \\
\text { Elastohydrodynamic (Present study) }\end{array}$} & Percentage (\%) \\
\hline Sitting ("Iftrasy") & Dry Contact [3] & & 3768.53 \\
Right leg & 119.7 & 3.09 & 2726.92 \\
Left leg & 130.4 & 4.61 & \\
\hline
\end{tabular}

The maximum deformation was found both in right and left leg on sitting movement which lie in two solid components, as shown in Figure 7. It is clear that the hydrodynamic pressure exerted by synovial fluid to the inner liner cup and femoral head is large enough to provide elastic deformation to the component.
Additionally, the deformation is equal to $1.61 \times 10 \mathrm{~mm}$ which that is much smaller compared with the existing clearance of $0.1 \mathrm{~mm}$, so the direct contact between inner liner cup and femoral head component is less likely to happen.

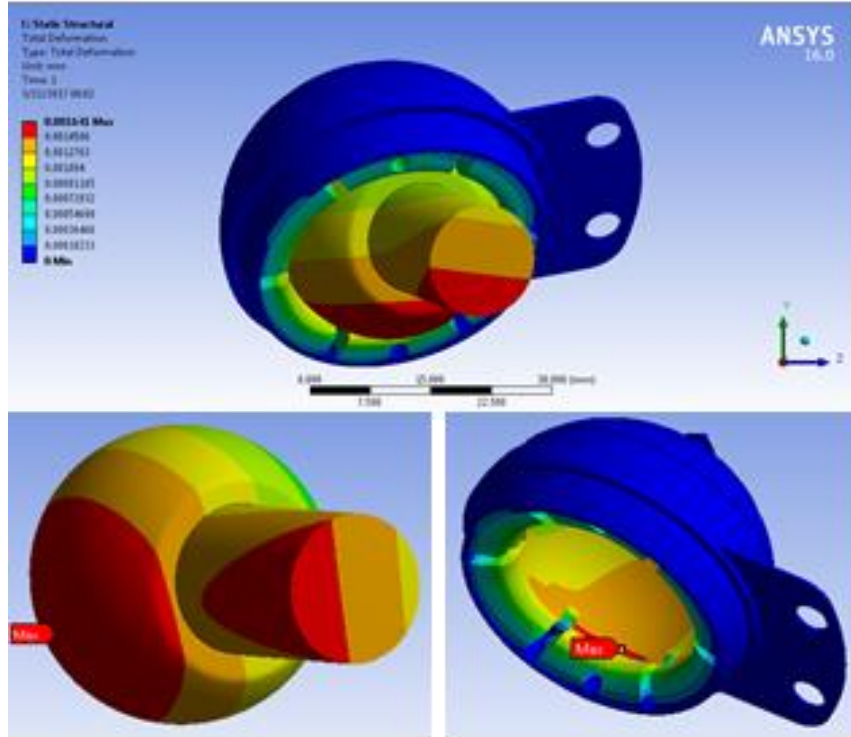

(a)

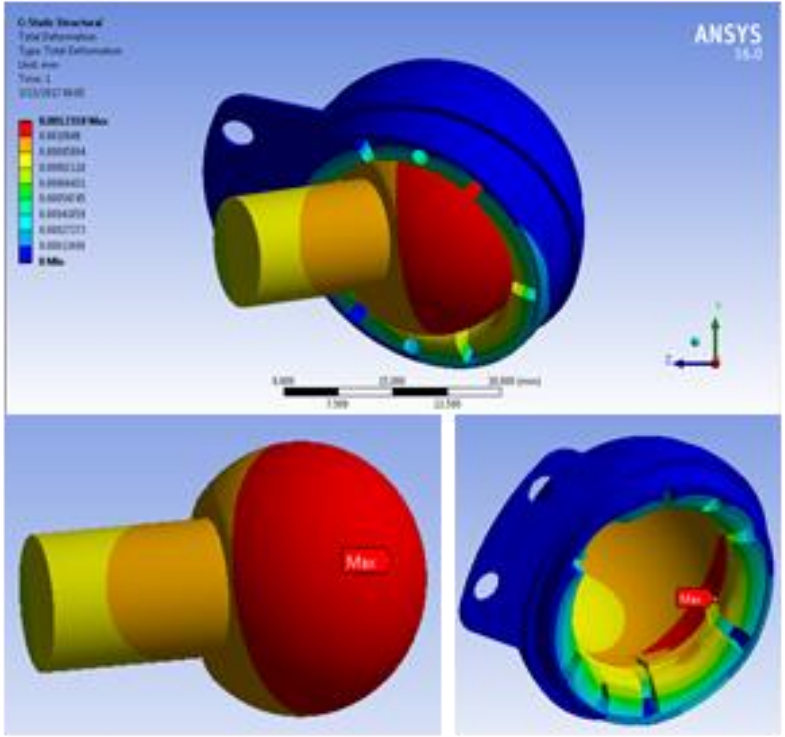

(b)

Figure 7 The deformation contour on sitting movement: (a) Right leg; (b) Left leg.

\section{CONCLUSION}

In this study, the performance of elastohydrodynamic lubrication model of artificial hip joint under sitting ("Iftirasy") (right and left leg) movement was performed simultaneously using fluid-structure interaction (FSI) method. The presence of synovial fluid demonstrated a significant difference in the von Mises stress result and the occurrence of impingement over the dry contact model. The model managed to reduce the von Mises stress considerably to a much smaller value. These findings suggest the necessity of modeling the synovial fluid lubricant in the artificial hip joint performance analysis. Besides, the deformation of the artificial hip joint has a relatively small result that indicates the impingement will most likely not occur. However, on the lubrication performance analysis, both the right and left leg positions had the opposing trend of the hydrodynamic pressure distribution. Thus, further investigation of load support analysis is required to confirm current results.

\section{ACKNOWLEDGMENTS}

The authors fully acknowledge the Directorate of Research and Community Service of Ministry of Research, Technology (DRPM-KEMENRISTEK), Indonesia, and Institute for Research and Community Services (LPPM), Diponegoro University, Indonesia, for the approved funding, which makes this important research viable and effective.

\section{REFERENCES}

[1] A.B. Legowo, "Simulation and evaluation of acetabular liner and femoral head of Undip model's total hip arthoplasty on prayer movement using the finite element method," (in Indonesian) B.S. Thesis, Univ. Diponegoro, Semarang, Indonesia, 2015.

[2] Y.A. Dhaneswara, "Analysis the effect of clearance on the wear and impingement of salat movement in 
the bipolar artificial hip joint's Undip model using the finite element method," (in Indonesian) B.S. Thesis, Univ. Diponegoro, Semarang, Indonesia, 2016.

[3] A.E.R. Gapa, "Hip joint biomechanics when walking and praying," (in Indonesian) B.S. Thesis, Univ. Diponegoro, Semarang, Indonesia, 2017.

[4] E. Saputra, I. Budiwan Anwar, R. Ismail, J. Jamari, and E. van der Heide, "Numerical simulation of artificical hip joint movement for western and Japanese-style activities," J. Teknol. (Sciences Eng., 2014.

[5] L. Gao, F. Wang, P. Yang, and Z. Jin, "Effect of 3D physiological loading and motion on elastohydrodynamic lubrication of metal-on-metal total hip replacements," Med. Eng. Phys., 2009.
[6] L. Mattei, F. Di Puccio, B. Piccigallo, and E. Ciulli, "Lubrication and wear modelling of artificial hip joints: A review," Tribol. Int., 2011.

[7] A. Ruggiero and A. Sicilia, "Lubrication modeling and wear calculation in artificial hip joint during the gait," Tribol. Int., 2020.

[8] L. Gao, D. Dowson, and R. W. Hewson, “A numerical study of non-Newtonian transient elastohydrodynamic lubrication of metal-on-metal hip prostheses," Tribol. Int., 2016.

[9] M. Tauviqirrahman, M. Muchammad, A. P. Bayuseno, R. Ismail, E. Saputra, and J. Jamari, "Estimation of appropriate lubricating film thickness in ceramic-on-ceramic hip prostheses," 2016. 